\title{
Teacher Perceptions of the Practicality and Effectiveness of Immersive Ecological Simulations as Classroom Curricula
}

\section{Citation}

Metcalf, Shari J., Amy M. Kamarainen, Tina Grotzer, and Chris Dede. 2013. “Teacher Perceptions of the Practicality and Effectiveness of Immersive Ecological Simulations as Classroom Curricula." International Journal of Virtual and Personal Learning Environments 4 (3) (July): 6677. doi:10.4018/jvple.2013070105.

\section{Published Version}

doi:10.4018/jvple.2013070105

\section{Permanent link}

http://nrs.harvard.edu/urn-3:HUL.InstRepos:37231553

\section{Terms of Use}

This article was downloaded from Harvard University's DASH repository, and is made available under the terms and conditions applicable to Open Access Policy Articles, as set forth at http:// nrs.harvard.edu/urn-3:HUL.InstRepos:dash.current.terms-of-use\#OAP

\section{Share Your Story}

The Harvard community has made this article openly available.

Please share how this access benefits you. Submit a story.

Accessibility 


\title{
Teacher Perceptions of the Practicality and Effectiveness of Immersive Ecological Simulations
}

\author{
Shari Metcalf ${ }^{1}$, Amy Kamarainen ${ }^{1}$, Cailean Cooke ${ }^{2}$, Selen Turkay ${ }^{1}$, Tina Grotzer ${ }^{1}$, Chris Dede $^{1}$ \\ ${ }^{1}$ Harvard University, USA \\ ${ }^{2}$ WestEd, USA
}

\begin{abstract}
Recent research with Multi-User Virtual Environments (MUVEs) in education has shown that these platforms can be effective and engaging for students; however, educators and administrators have practical concerns about the adoption of MUVE-based curricula. This study looks at implementations of EcoMUVE, a MUVE-based curriculum designed to support middle school learning of ecosystem concepts and processes. Research questions looked at teacher perceptions of the curriculum's implementation feasibility, alignment with curricular objectives and standards, and perceived value. Results showed that EcoMUVE was very well-received, and technical issues were manageable. Teachers felt the curriculum was effective, aligned well with standards, and compared favorably with a non-MUVE alternative. Particular technological and curriculum features that contributed to EcoMUVE's perceived value included student-directed learning, an inquiry, role-based pedagogy, immersion in the virtual environment, and the ease of collecting and comparing data with graphs.
\end{abstract}

Keywords: MUVE, EcoMUVE, Interactive learning environment, Simulation, Virtual reality, Teacher Perceptions, Feasibility

\section{INTRODUCTION}

Multi-user virtual environments (MUVEs) are 3D graphical worlds used to enable simulated immersive experiences. MUVEs are considered a promising platform for educational applications, in part because they can simulate environments and experiences otherwise impossible in school settings. MUVEs provide rich environments in which participants can interact with digital objects and tools, with each other, and with computer-based agents. Immersion in virtual environments can transform the learning experience by empowering new forms of engagement, self-efficacy, mastery, and transfer (Dede, 2009). Recent research with MUVEs for science education has shown that these platforms can be effective in engaging students and fostering deeper learning (e.g., Barab, Thomas, Dodge, Carteaux, \& Tuzun, 2005; Dede, 2009; Clark, Nelson, Sengupta, \& D’Angelo, 2009; Ketelhut, Nelson, Clarke, \& Dede, 2010; Schaller, Goldman, Spickelmier, Allison-Bunnel, \& Koepfler, 2009). Positive learning impacts have also been demonstrated for similar types of virtual tools, including game-based curricula and multi-agent-based computational models (Barab, Pettyjohn, Gresalfi, Volk, \& Solmou, 2012; Dickes \& Sengupta, 2013).

Despite the potential benefits of MUVEs, however, practical concerns remain about their inclusion in school curricula (Jones \& Warren, 2011; Kenny \& McDaniel, 2009; Klopfer, Osterweil \& Salen, 2009; Rice, 2007). Barriers to implementation include concerns about instructional effectiveness, lack of alignment to standards, lack of sufficient technology, need for teacher training, and limitations on time and schedule. A study on the perspectives of K-12 educators on the use of MUVEs in classroom settings (Jones \& Warren, 2011), found that the fourteen teachers and administrators surveyed mostly chose not to 
implement 3-D virtual environments in their classrooms because of concerns about instructional effectiveness, technology, and time.

These concerns mirror topics raised by studies of the adoption of new technologies more generally (Ertmer, 2005; Miranda \& Russel, 2012; Venkatesh, Morris, Davis, \& Davis, 2003). Factors that may influence decisions about whether to adopt emerging technologies include: facilitating conditions (i.e., a user's perception that sufficient infrastructure exists to implement a new technology) and performance expectancy (i.e., a user's perception that a new technology will enhance his or her job performance) (Venkatesh, et al., 2003). Researchers have shown that these factors influence teachers' technology adoption - in a study of Massachusetts educators, teachers' ease or difficulty integrating technology into instruction, belief that technology will help accomplish instructional goals, and perceived importance of technology for teaching were found to be strong predictors of their technology use in the classroom (Miranda \& Russel, 2012).

Teacher perceptions of new technologies matter. While decisions about integration often come from the district or school level, it is teacher acceptance and action on an individual level (whether or not a teacher adopts an innovation and how he or she incorporates it into instruction) that determine the technology's implementation success (Straub, 2009). Yet, at present, there is minimal research about teachers' acceptance or rejection of new technologies (Ifenthaler \& Schweinbenz, 2013). This is surprising as teachers are the gatekeepers of new technologies in the classroom (Ertmer, 2005), and many new technologies fail for lack of user acceptance.

Given teachers' key role in educational technology implementation and the importance of teacher perceptions as a predictor of the eventual adoption of new technologies, we focused our research on teacher perceptions of the feasibility and utility of an educational MUVE curriculum called EcoMUVE.

EcoMUVE (ecomuve.gse.harvard.edu) is a middle school science curriculum developed through a research grant from the Institute of Education Sciences (IES). It aims to harness the affordances of virtual worlds - e.g., zooming in to the microscopic level, traveling to different points in time, and seeing effects emerge across time and distance - to accomplish understanding goals about causal patterns in ecosystems that are otherwise difficult to achieve (Metcalf, Kamarainen, Tutwiler, Grotzer \& Dede, 2011). Research with EcoMUVE in the classroom has shown promising results on gains in student learning and motivation (Grotzer, Kamarainen, Tutwiler, Metcalf, \& Dede, 2012; Metcalf, Tutwiler, Kamarainen, Grotzer, \& Dede, 2013; Metcalf, Chen, Kamarainen, Frumin, Vickrey, Grotzer, \& Dede, in press).

We examined the perceptions of teachers who implemented the EcoMUVE curriculum in their classrooms about the curriculum's practicality and effectiveness. Some teachers additionally participated in a comparison study of EcoMUVE with a non-MUVE curriculum - using the EcoMUVE Pond module with half their classes and a similar, non-MUVE-based curriculum with the other half. Data collected from teachers included post-surveys, post-interviews, and daily self-reports of teacher experiences using the curriculum in the classroom. We summarized surveys and interviews with teachers during and after the use of EcoMUVE in their classrooms, in order to determine their perceptions of its value, effectiveness, and feasibility based on their experiences.

\section{METHODS}

\section{Nature of the Intervention}

The EcoMUVE curriculum consists of two MUVE-based modules, Pond and Forest. Each module consists of ten 45-minute lessons. Teachers can choose to use either or both modules, so the unit takes either two or four weeks. Each module represents an ecological scenario involving complex causality. The curriculum is inquiry-based; students investigate research questions by exploring the virtual 
ecosystem and collecting data from a variety of sources over time. The curriculum uses a jigsaw pedagogy; students work in teams of four and are given "roles" - areas of expertise (e.g., botanist, microscopic specialist). Students use interactive learning quests to learn more about the content specific to their module, (e.g., what is $\mathrm{pH}$ ). Each student performs data collection specific to their roles, and then shares their data with their teammates within the software, via tables and graphs. Each team works collaboratively to analyze the combined data and understand the ecosystem interrelationships. The module culminates in each team creating an evidence-based concept map representing their understanding of the causal relationships in the ecosystem and presenting it to the class.

During the curriculum, students work individually on computers to explore the 3D immersive environment, but can chat and share data with their teammates, and see each other's avatars. There are also opportunities for teams to meet together and work collaboratively on their concept maps and presentations. Teachers introduce activities, provide guidance and support to students as they work individually on computers or together with their teams, and lead whole-class discussions on ecosystem topics linked to the students' experiences in the virtual world.

EcoMUVE supports students gaining a deeper understanding of ecosystem relationships via immersive simulation. For example, in the EcoMUVE Pond module (Figure 1), students explore the pond and its surroundings, including a nearby golf course and a housing development, and talk to local "residents" (Figure 2). They use a camera tool to take photos of organisms and learn about them in an online field guide. They visit the pond over a number of virtual days, eventually making the surprising discovery that on one day all the large fish have died, and are tasked with figuring out what happened. Through exploration, students discover that fertilizer runoff from the development is the distant cause of an algae bloom at the pond. A submarine tool allows students to explore microscopic organisms, including the algae and bacteria that play critical roles in the pond ecosystem (Figure 3). They collect data on water measurements such as dissolved oxygen, phosphates, nitrates, $\mathrm{pH}$, and turbidity (Figure 4). Teams use tables and graphs to view and analyze data over time (Figure 5). 


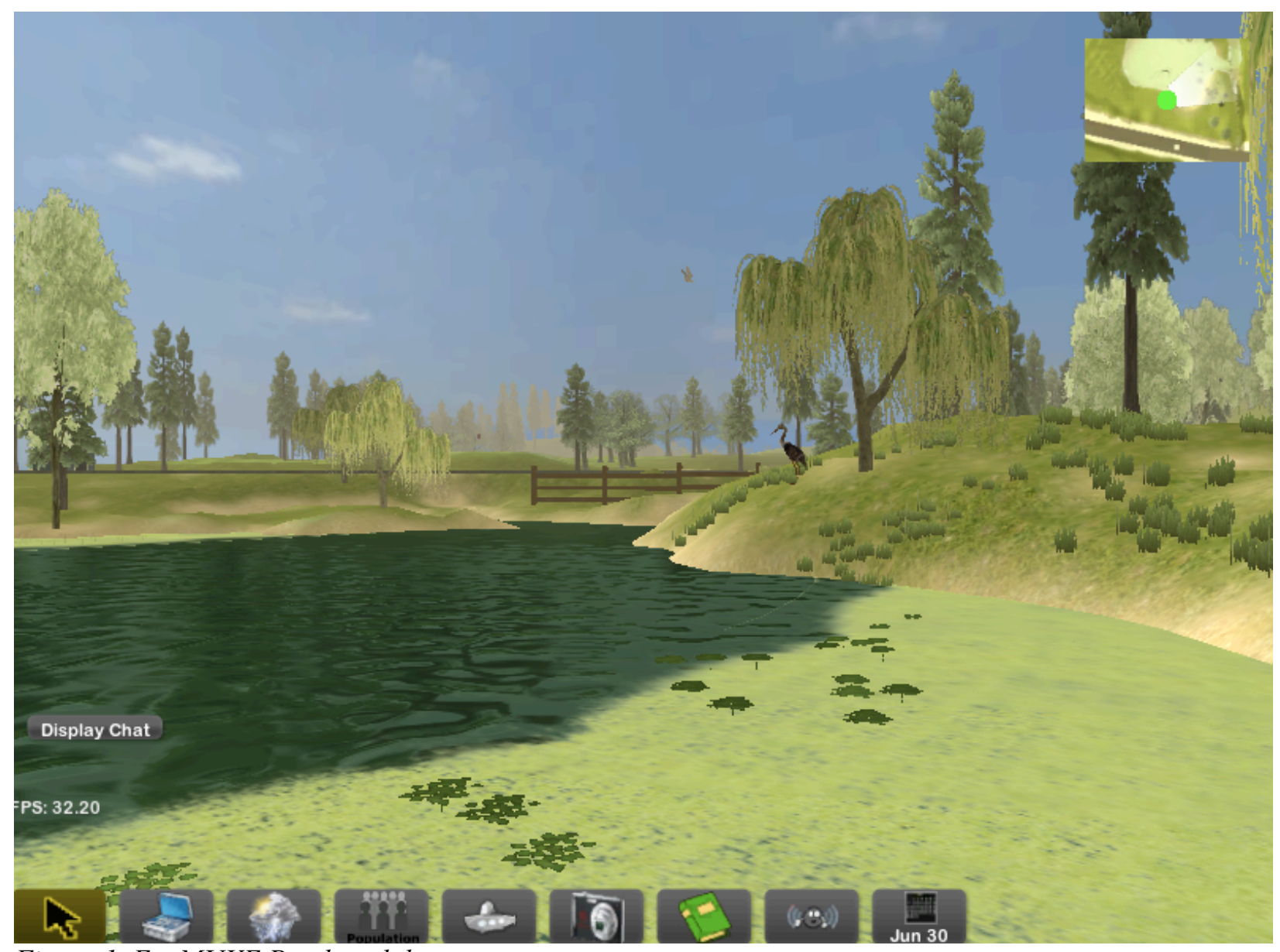

Figure 1. EcoMUVE Pond module 


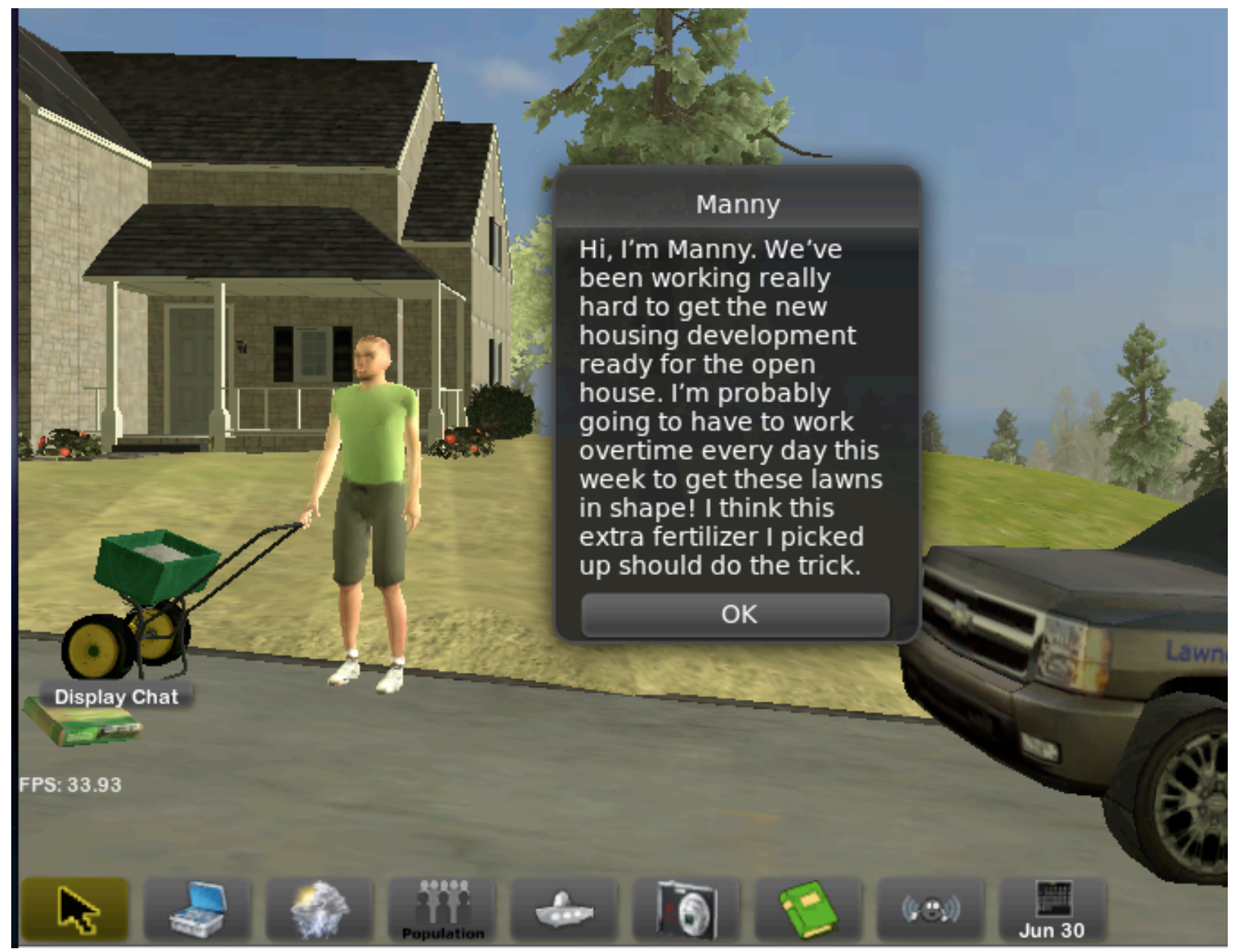

Figure 2. An in-game avatar, or non-player character (NPC) 


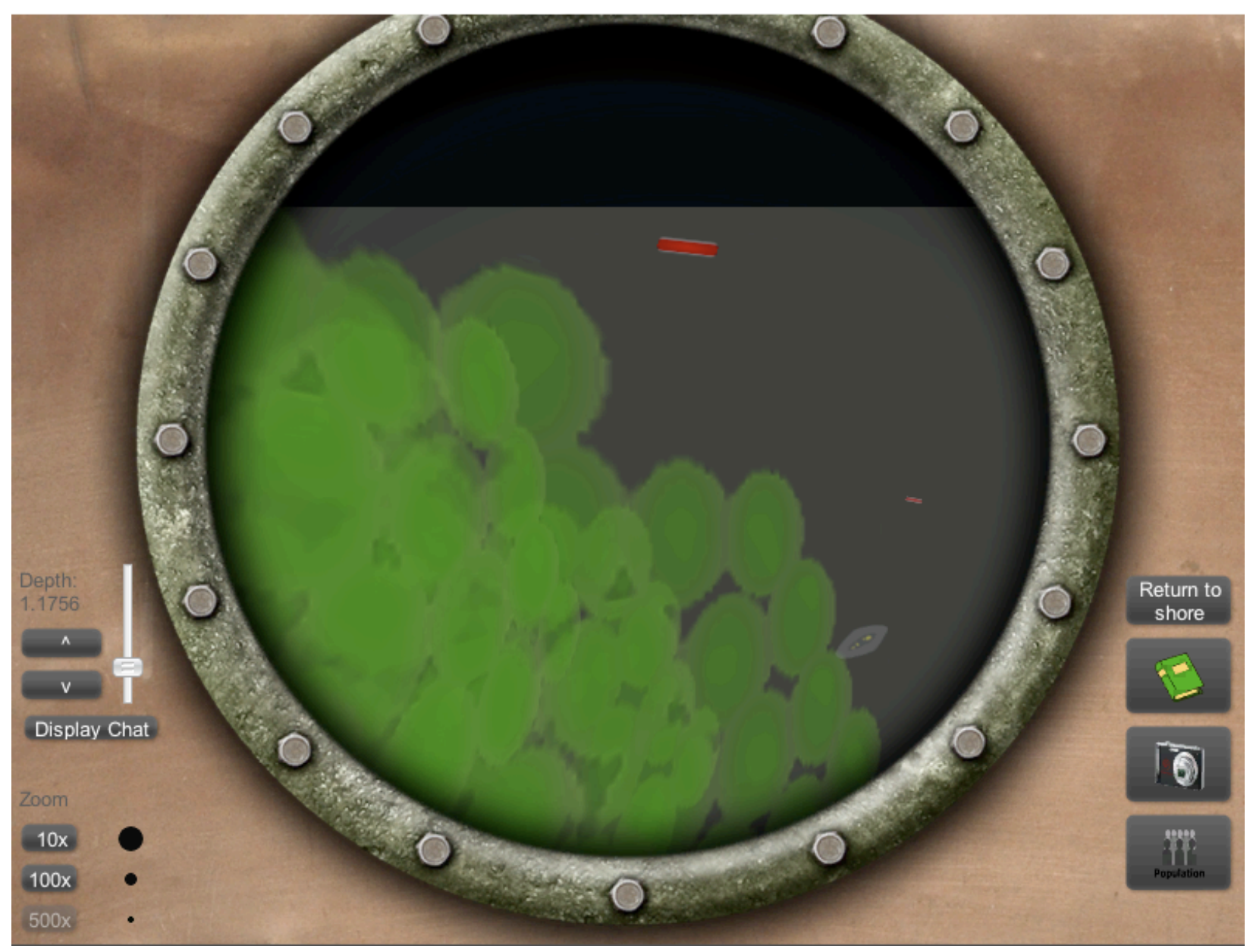

Figure 3. Viewing microscopic organisms in a virtual submarine 


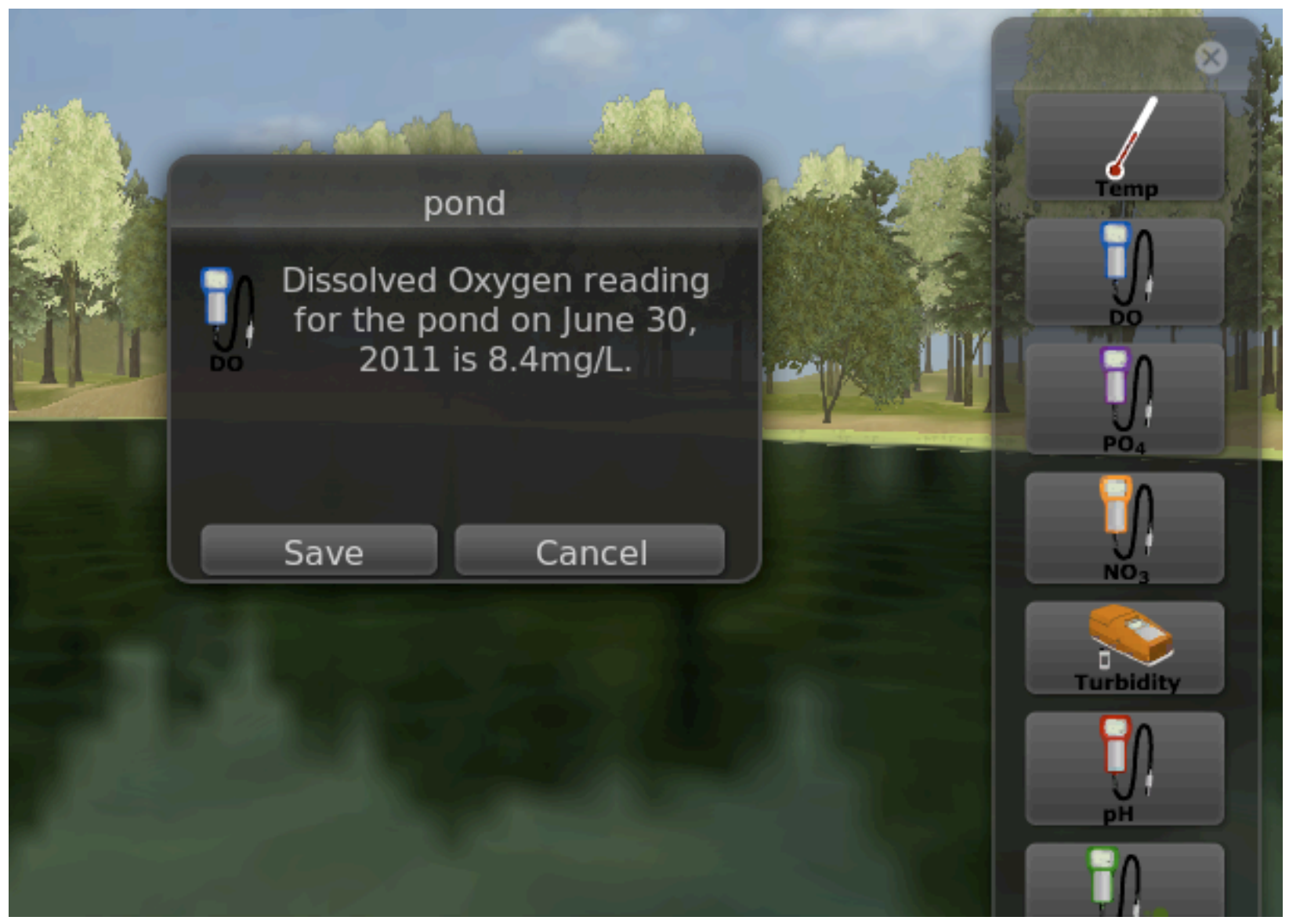

Figure 4. Data collection of water measurements

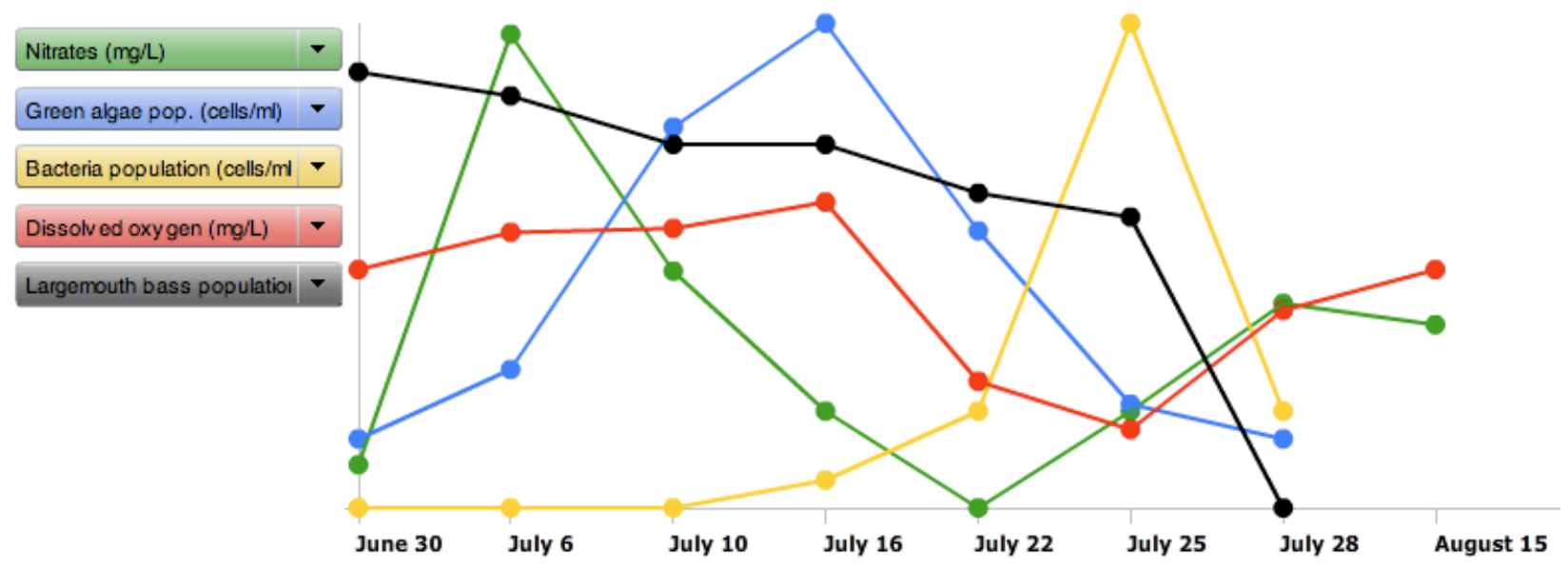

Figure 5. Tables and graphs to view and analyze data

\section{Research Questions}

The EcoMUVE research project is designed as a feasibility study on the practicality, integration, and acceptance of the MUVE-based curriculum for student engagement and learning. 
For this paper we focus on teacher perceptions of EcoMUVE. The research questions we will address center on four areas: implementation feasibility, alignment with curricular objectives and standards, perceived value, and comparison with a non-MUVE curriculum:

- RQ 1: Do teachers see usage of the EcoMUVE curriculum in typical school settings as feasible from a practical perspective?

- RQ 2: How, if at all, do teachers think the EcoMUVE curriculum fits within their plans for curricular objectives, local and national standards, and student achievement?

- RQ 3: How do teachers perceive the impact of the EcoMUVE curriculum in terms of student engagement and learning?

- RQ 4: (Comparison study) What do teachers see as the relative strengths and weaknesses of the MUVE curriculum as contrasted to the non-MUVE comparison curriculum?

Additionally, we are interested to see what issues emerge through teacher feedback - what specific features of the technology or the pedagogy impact the teachers' perceptions of the practicality and effectiveness of the EcoMUVE curriculum.

\section{Study Design}

During January-June, 2011, we tested the EcoMUVE curriculum with 18 th to 9th grade science teachers and approximately 1330 students in 6 school districts in 3 Northeastern US states. Seven of the teachers participated in the comparison study. Table 1 shows the number of teachers, classrooms, and approximate number of students participating in the study, which modules they used, and whether they participated in the comparison study. One 5th grade teacher, nine 7 th grade teachers, five 8 th grade teachers, and three 9th grade teachers were involved in the study.

Table 1: Numbers of participants in EcoMUVE studies Jan-June 2011

\begin{tabular}{|l|l|l|l|}
\hline & Teachers & Classrooms & Students \\
\hline Pond & 3 & 7 & 150 \\
\hline Pond+Comparison & 9 & 34 & 700 \\
\hline Forest & 4 & 14 & 300 \\
\hline $\begin{array}{l}\text { Pond+Comparison and Forest } \\
\text { (4 weeks) }\end{array}$ & 2 & 8 & 180 \\
\hline TOTAL & 18 & 63 & 1330 \\
\hline
\end{tabular}

Teachers participated in the project on a voluntary basis. Two teachers requested participation individually, after hearing about the project independently. The other 16 teachers were recruited through the encouragement of their principal or district science coordinator.

\section{Comparison Curriculum}

For the comparison study, teachers taught two to four comparable classes using EcoMUVE Pond or a comparison curriculum with half their classes. The comparison curriculum, Lawrence Hall of Science Environmental Detectives (Beals \& Willard, 2001) is also inquiry-based and covers a similar "fish kill" scenario. Students read descriptions of the ecosystem and statements of various "suspects," and integrate the information with their own hands-on test results ( $\mathrm{pH}$, turbidity, and phosphates). The curriculum was 
modified to fit the two week schedule and included some of EcoMUVE's non-MUVE materials and discussions in order to make sure that comparable materials were covered.

\section{Data Collection}

Data collected from teachers included post-surveys, post-interviews, and daily self-reports of teacher experiences using the curriculum in the classroom. Survey questions were open-ended and invited explanation; responses were coded based on clear categories (e.g., yes/no) and further analyzed for emergent patterns and trends.

Teachers based their judgments about EcoMUVE on their personal experiences teaching the curriculum to their students: their class discussions and conversations with students, their observations of students' activities, and the artifacts produced by their students, particularly the final concept map presentation by each student team. It should be noted that, while the project researchers also collected student assessments on affective measures, science content, and causal understanding, which are reported elsewhere (e.g., Grotzer, Kamarainen, Tutwiler, Metcalf, \& Dede, 2012; Metcalf, Tutwiler, Kamarainen, Grotzer, \& Dede, 2013), those assessments were not available to the teachers at the time they were surveyed about their perceptions of the curriculum, and the teachers did not conduct any formal assessments of their students other than the student teams' concept maps and presentations.

\section{RESULTS}

First we report a summary of teachers' answers to specific post-survey questions. Post-surveys were received from 16 of the 18 participating teachers. When reporting results on survey questions, first the answers are summarized, with illustrative quotes from teachers, and then specific issues are described. Second, we report on emergent themes drawn from the post-surveys as well as post-interviews with five teachers, and daily logs from 13 of the 18 teachers.

\section{Teacher Post-Survey Results}

RQ1 Feasibility: "Do you see usage of EcoMUVE in typical school settings as feasible from a practical perspective?"

14 out of 16 teachers gave "yes" answers, one said "yes and no," and one left it blank. The biggest issue, raised by nine teachers, was simply access to technology. Computers tend to be a scarce resource at schools, and it was "difficult to get computer lab time for 2 weeks in a row." In a post-interview, one teacher recommended:

Schools need to have enough computer lab space and enough leeway that they can have a computer lab booked for an extended period of time. Quite frankly that was the biggest nut to crack around here.

Other specific issues included the need for high-speed Internet access (mentioned by 2 teachers), sufficiently powerful computers ( 2 teachers), training ( 1 teacher), and enough time (1 teacher).

Two teachers highlighted the design of the materials as a positive feature in terms of feasibility; one said, "it takes students into a virtual world... and shares with them a real-world situation," and another said, "it teaches scientific thinking and concepts in such a novel meaningful way." Other reasons teachers gave in support of EcoMUVE's feasibility included its student-friendliness (mentioned by 2 teachers), customizable lessons ( 1 teacher), online materials ( 1 teacher), and that it took just the right amount of time (1 teacher). 
RQ2 Compatibility with standards: "How do you think the EcoMUVE curriculum fits within your plans for curricular objectives, local and national standards, and student achievement?"

All 16 teachers indicated that the curriculum fit very well. One teacher elaborated:

It fits perfectly with our 8th grade curriculum on the local level, the objectives were appropriately accessible to most students and it meets the curricular standards of critical thinking, ecosystem dynamics and relationships, and interpreting graphic trends.

Another teacher mentioned that "it really models what is done in the field with various scientists collecting data and coming together to solve a problem, very real world."

RQ3 Perceptions of the impact on student engagement and learning: "How well do you think EcoMUVE supported each of the following:
a. student engagement.
b. student learning of science content.
c. student learning of complex causality in ecosystems.
d. student learning of inquiry."

Teacher responses for each category were coded on a scale of 1-5 (5=excellent, 4=good, $3=$ medium, $2=$ fair, $1=$ poor). The results shows that teacher ratings in each category ranged between good and excellent, receiving average ratings of 4 or better. Table 2 displays the average ratings for each category.

Table 2: Average teacher ratings of student engagement and learning, on a scale of scale of 1-5 ( $5=$ excellent, $4=$ good, $3=$ medium, $2=$ fair, $1=$ poor $)$.

\begin{tabular}{|l|l|}
\hline & Average Rating \\
\hline Engagement & 4.3 \\
\hline Science content learning & 4 \\
\hline Complex causality learning & 4.1 \\
\hline Inquiry learning & 4.3 \\
\hline
\end{tabular}

Student Engagement (average 4.3 out of 5): Teachers reported that "students love the technology." Only one teacher mentioned the distraction of the game-like environment, noting that, "Students were always engaged in exploring the world, but not always engaged in the task at hand."

Student Learning of Science Content (average 4 out of 5): One teacher added that EcoMUVE helped students synthesize their learning, saying "EcoMUVE was almost like a culminating project for them. It gave students the ability to apply what they have learned in class."

Student Learning of Complex Causality in Ecosystems (average 4.1 out of 5): Several teachers felt that this was the strongest part of the curriculum. One wrote:

In my experience, students can individually learn the important components of ecosystems which include, photosynthesis, energy conversion, conservation of matter, cycles, populations, food chains, and food webs but often cannot tie it all together and realize that ecosystems are dynamic and really the study of the relationships of living things and their environment. EcoMUVE definitely showed complex causality. 
Other teachers felt that learning of complex causality depended on student level: "more advanced learners made connection, a good deal did not," and that more time or direct instruction might have been helpful.

Student Learning of Inquiry (average 4.3 out of 5): Teachers were particularly enthusiastic about students being "actively engaged with the process of inquiry and investigation."

RQ4: Comparisons with the non-MUVE curriculum: "If you used both the Pond EcoMUVE and the Environmental Detectives curricula, please describe any differences you observed between the curricula in:

a. student engagement.

b. student learning of science content.

c. student learning of complex causality in ecosystems.

d. student learning of inquiry.

What do you think might have been responsible for those differences?"

We looked at how teachers described the differences and coded for whether they rated EcoMUVE better, the comparison curriculum (ED) better, or both about the same, for each category. On average, the seven teachers who responded rated EcoMUVE higher than ED in all four categories (Table 3).

Table 3: Percentage of teachers who rated EcoMUVE better, the comparison curriculum (ED) better, or both about the same, for each category.

\begin{tabular}{|l|l|l|l|}
\hline & EcoMUVE better & ED better & About the same \\
\hline Engagement & $57 \%$ & $14 \%$ & $29 \%$ \\
\hline Science content learning & $43 \%$ & $29 \%$ & $29 \%$ \\
\hline Complex causality learning & $29 \%$ & 0 & $71 \%$ \\
\hline Inquiry learning & $29 \%$ & 0 & $71 \%$ \\
\hline
\end{tabular}

In general, teachers indicated the primary advantages of EcoMUVE were (1) that students were more active in learning and (2) that the information was more visual. One teacher explained:

The freedom to walk and click wherever they want allowed students to stumble upon questions. Most of the virtual world was familiar to students, but many question marks existed within the virtual world. As soon as one person found something perplexing, the whole class wanted to investigate it too. Everyone was participating together, at their own pace. With ED, activities were much more passive and students waited for something to engage them.

Another teacher summarized:

Overall, ED students did not see the big picture clearly where EcoMUVE students did. They visually saw something was up in the world and physically were able to collect data. ED kids relied on eyewitness accounts and testing.

Teacher explanations in specific categories revealed the following findings.

Student Engagement: Engagement was seen as better in EcoMUVE, both because of the technology and the student self-directed activities. Teachers also noted that sometimes students were so fascinated by the interface they did not pay attention to the learning experience. 
Student Learning of Science Content: Content knowledge learning was also seen as better in EcoMUVE. Teachers described the value of EcoMUVE in including more data collection and analysis. Of the teachers who described ED as better, one referred to an illustration in the ED materials, and the other mentioned said that as ED was a "very teacher facilitated" curriculum they felt able to spend more time directly reviewing concepts with their students.

Student Learning of Complex causality in Ecosystems: Complex causality learning was seen as better in EcoMUVE, but mostly the two curricula were seen as similar. Teachers who rated EcoMUVE higher mentioned its support for students to "plot and analyze trends," which helped them "really piece their ideas together nicely during their final presentations."

Student Learning of Inquiry: Inquiry learning was also seen as slightly better in EcoMUVE. Teachers who rated EcoMUVE higher noted that EcoMUVE students asked more questions and worked more independently. One teacher noted that the "graphing function was a powerful tool to encourage students to look at pieces of data and make connections between them."

\section{Emergent Themes}

During interviews, teachers were asked to describe what they particularly liked or disliked about the EcoMUVE curriculum. Some teachers also kept daily logs during their use of the curriculum, primarily to record details of each day's implementation, but also to add notes about anything that went particularly well or badly, or anything they would change in the future. We coded the interview and log responses for emergent themes - issues or features that were mentioned by at least three teachers as something they found especially important. In reporting this data, we first describe each theme, and then give an example teacher quote that exemplifies it, highlighting in bold the words identifying the theme.

Student-Directed Learning: A major theme that emerged through the interviews and post-surveys was the issue of student-directed learning. Three teachers described wanting more control, whereas five teachers specifically mentioned the value of students having freedom to explore, including one who experienced both sides.

I think that a little bit more guided, structured time that forces them to engage with every tool would be helpful.

I observed that the students greatly enjoyed the freedom and independence to explore the pond ecosystem online. I also think they were also able to ask questions, and then, almost immediately, collect data to answer them.

The teacher who recognized both sides of the issue in herself explained:

One thing, as a teacher, about the virtual world that frustrated and kind of scared me a little was I felt less in control of their learning. They're exploring and navigating and most of the time doing a really good job of it, but I just wanted to be like - but I want to tell you what you're supposed to see-you know, I wanted to - but that just comes from my-I need to let go of that, and understand that built in the program is what they need to find out, so me telling them is not necessarily better than them finding it out-or maybe it is better for them to find it out themselves. 
Technology Features: We looked for any software features that the teachers perceived to be particularly valuable about the MUVE environment, beyond the virtual world itself, which teachers saw as "exciting" and "super cool" for students. Three teachers specifically mentioned the value of walking around the virtual environment for seeing and noticing the relationships in an ecosystem.

It was very interesting for them to go into an environment and look around, though, and notice that one thing affects another in the environment. [...] they had to go around and realize that one part of the world affected another part, like the fertilizer affected the pond.

Five teachers also described the ability to easily collect and compare data using graphs as particularly valuable for understanding how variables change over time. One teacher described it as:

Students were able to really focus not only on what they saw in the world, but really focus on the graphs and their data. That's a really huge skill that I think is really hard to teach. And having the data available for them to then analyze and the ability to graph it with the click of the mouse, takes away the nuts and bolts of it, and really gets down to - what does the graph mean, what does the data mean.

Inquiry, role-based pedagogy: Beyond the MUVE itself, teachers also valued the inquiry, role-based pedagogy. Teachers specifically mentioned active, hands-on exploration, students' investment in the activity, and the value of students taking on specific roles and working with a team.

I wish I could do more active learning, and take them on more field trips, but we can't. So this allows us to be more exploratory. And we also don't have a lot of lab tools that I can teach with either, traditional laboratory tools, or those probes, so having them do it in a virtual environment is fantastic.

Their investment in it was so much greater. I mean, I could take kids outside to do observations and after ten minutes, there would be students who would be picking flowers, and other off-task. While this program has some ability to do that... they really were mostly focused most of the time on what they were doing. It really kept them engaged.

Each student role brings a separate piece of the puzzle to the table. It is great to see the exchange of ideas, positive debates and great conclusions. Students are realizing that many factors have caused the fish to die and they are using data to support their ideas.

\section{DISCUSSION}

After using EcoMUVE, teachers felt that the curriculum was feasible, well-aligned with standards, and supported student engagement and learning of science content, complex causality, and inquiry. In addition, teachers perceived EcoMUVE as having multiple advantages over a similar non-MUVE curriculum. This suggests that teachers perceived positive performance expectancy - they found the new technology improved their job performance by facilitating instruction and students' learning.

According to the Unified Theory of Acceptance and Use of Technology, which Venkatesh et al. have found explains up to 70 percent of user acceptance of new technologies, performance expectancy is the strongest predictor of behavioral intention (Venkatesh, et al., 2003). The themes that emerged from the teacher interviews, surveys, and daily records showed that teachers perceived the MUVE-based 
curriculum as a valuable instructional tool. This related not only to features of the MUVE - exploration, visualization, graphing - but also features of the curriculum within which the MUVE was used. The perceived value of the virtual environment of EcoMUVE is closely tied to its hands-on, inquiry, rolebased curriculum. For example, we saw that the teacher's own comfort or discomfort with studentdirected learning influenced their perceptions of the value of EcoMUVE.

Yet, in revisiting educators' concerns about MUVEs (e.g., Jones \& Warren, 2011), we also acknowledge that teachers also identified issues with facilitating conditions - technology access, and to a lesser extent, time (even with the benefit of administrative support) as impacting their ability to implement the curriculum. In addition, during the study, many teachers had to navigate technical difficulties, such as district firewalls, issues with installing the Unity webplayer required to run the software, student logins, internet connectivity, and accommodating different types and versions of web browsers, operating systems, and platforms. This is concerning, as a lack of facilitating conditions may prevent teachers from being able to use EcoMUVE. According to Venaktesh et al., technical infrastructure supporting new technologies is essential for their adoption (Venkatesh, et al., 2003). As computer access improves across all schools, we are hopeful that technological barriers will fade.

It is important to acknowledge that this was a self-selected group of teachers. All of the teachers had agreed to participate voluntarily and were paid a small stipend for the extra time required to participate in training and to collect the research data. However, we note that none of the teachers had ever used any software similar to EcoMUVE before in their classes, so they really didn't know what to expect. We especially consider it a strong positive result that that they remained enthusiastic at the end of the unit. When asked if they were interested in participating next year, all 16 teachers surveyed expressed strong interest in using the curriculum again next year.

\section{ONLINE STUDY}

While our findings suggest that after using EcoMUVE teachers perceived it as something that facilitated instruction and student learning, it will be important to convey this information to other educators (potential EcoMUVE users), to encourage them to try the software. Researchers have shown that teachers who use technologies aren't always clear on how it can improve their instruction and facilitate learning (Ifenthaler \& Schweinbenz, 2013). Even teachers who have a positive attitude towards incorporating a new technology may still be skeptical of its educational benefit, yet teachers' perceptions of new technologies may change, particularly in the early stages of introduction and integration (Ibid).

Beginning in May, 2012, EcoMUVE was made available for download through a free license from Harvard University. By registering their contact information, interested parties are given access to a webpage that provides a downloadable version of the software, the full curriculum and teacher's guide. This allows us to keep track of how many people are interested in EcoMUVE. By April 2014, 830 people had registered with the website.

We conducted a follow-up study with this on-line population in order to investigate the perceptions of EcoMUVE by this larger group of teachers who had chosen to download and implement EcoMUVE on their own. The survey had 12 questions, of which five were multiple choice and seven open-ended. Multiple-choice questions asked participants their role, which EcoMUVE modules they used, with how many students had they used it, and whether they would be using EcoMUVE next year. Open-ended questions asked for details on how participants used the EcoMUVE curriculum. Though we did not ask directly about perceived feasibility of the EcoMUVE curriculum, compatibility with the standards, or perceptions on student engagement and motivation, the participants' answers to the open-ended questions provided insights on their perspective of EcoMUVE in regards to first three research questions. 


\section{Methods}

In April 2014, the survey was sent to the 830 people who were currently on the mailing list. Participation was voluntary. In total, 96 people started the survey. The majority were female (female $=62$, male $=30$, N/A=4) and were located in the USA (13 were outside of USA). Five participants dropped the survey. Twenty-six people reported that they had not or had no plans to use EcoMUVE, and were therefore directed to the end of the survey without completing the open-ended questions. As a result, we report on the responses of 66 participants, of whom $86 \%$ were K-12 teachers, who answered the complete the survey, including the open-ended questions. Sixteen (out of 66) had not yet used the EcoMUVE when they answered the survey, but talked about their plans to use the curriculum in the future.

A top-down approach was chosen to analyze data and Nvivo 9.0 qualitative analysis software was used to do the analysis. Teacher responses are reported using de-identified survey IDs.

\section{Results}

RQ1 Feasibility: Do teachers see usage of the EcoMUVE curriculum in typical school setting as feasible from a practical perspective?

Technology access and technical compatibility: Teachers' access to technology varies. In some schools each student has an individual MacBook computer. In others, teachers have two computers for the entire classroom. Teacher ID25 said, "We have very limited access to technology. Our computers are 7 years old and only have 1GB of RAM. Priority for computer usage is given to math and ELA." Twenty-seven teachers reported students were each on individual computers during the EcoMUVE activities. Twentyone teachers had students work in groups (usually pairs) on shared computers. Some teachers let students download the EcoMUVE software on their personal laptops and bring them to the classroom.

Thirteen teachers reported some sort of technical difficulty because of insufficient technological capacity at their school. Nine teachers asked for mobile app or web-app versions of EcoMUVE because their schools have iPads or Chromebooks rather than computers for each student.

The teachers' familiarity with the EcoMUVE virtual environment was an important factor in determining the success of the curriculum implementation. $62 \%$ of respondents used EcoMUVE only once. Those who used the curriculum for three years or more (16\%) emphasized students' engagement with the curriculum. An $8^{\text {th }}$ grade teacher, ID29, said, “... It was a little difficult for me trying to stay one step ahead of the kids. And some things we just had to figure out while in the program." She added that, now that she had been through the program once, she felt more comfortable, and expected that she would do a better job teaching the program next time. Others who had used EcoMUVE previously mentioned that their prior experience with the software allowed them to modify the curriculum to fit their classroom needs. A representative quote:

The first year was a learning process but the following year I found I had to scale down the program to meet the level of students in the classroom. I have found that 6th grade students don't have enough prior knowledge about the chemistry to utilize the full curriculum... (ID68, 6th grade teacher, NJ, USA)

Similar to the above, many other teachers also reported customizing the curriculum to fit with their classroom teaching. Some teachers condensed lessons, or otherwise changed the timeframe. Others appropriated activities from EcoMUVE for use in their own curriculums, or inserted their own lessons 
into EcoMUVE. Some changed the roles of students, either to adjust responsibility or numbers. In several cases, the students had either prior knowledge, or deficits, and so the instructors shifted the emphasis of the materials to adapt to their students needs. Several developed and used additional materials, such as rubrics, worksheets, and Google docs.

Some teachers talked about slight disadvantages of game-like features of the virtual world that interfered with their teaching. The most common complaint was that students wanted to just explore the virtual world without paying much attention to the lessons in the first few sessions. A $7^{\text {th }}$ grade teacher, ID95, said that her biggest hurdle was sharing the data, but she finally worked it through. Several teachers said that EcoMUVE ran smoothly on their school computers compared to some other software they used at their school.

In summary, most teachers became more comfortable with EcoMUVE after their first implementation, and they often customized the EcoMUVE curriculum to their classroom needs. Except for some difficulties with technology accessibility, teachers did not report any major challenges. These findings confirm the results from the earlier study on the feasibility of the curriculum.

RQ2 Compatibility with standards: How do teachers think the EcoMUVE curriculum fits within their plans for curricular objectives, local and national standards, and student achievement?

As mentioned above, teachers customized the curriculum to their classroom teaching as it fit with their curricular goals. They used EcoMUVE curriculum in three ways, as a main, complementary, or parallel curriculum.

Some teachers used the EcoMUVE curriculum as the main curriculum, with other lesson plans to supplement it. For instance, teacher ID28 said, "I used all of the activities in the pond curriculum, mostly adhering to the lesson plans in the curriculum guide. I supplemented with other materials as well and was working on 'Bio-Bottles' at the same time to be able to link concepts in your pond ecosystem to our biobottle ecosystem in our class."

Seventeen teachers said they used the curriculum to complement their own, and to introduce students to concepts like fieldwork. Six out of seventeen coupled the EcoMUVE curriculum with actual fieldwork or a trip to a nearby pond or forest. For instance, ID69 used the curriculum as a practice for a pond study they were planning on completing at a local pond. Another reason teachers said they used the curriculum was to introduce students to a pond environment when it was not possible to visit a nearby pond.

The third use of the curriculum was to reinforce teachers' main curriculum. For instance, a $5^{\text {th }}$ grade teacher from Pennsylvania, ID96, said that she used the curriculum as an application platform for her unit on ecology because "there has been a dramatic increase of Deer ticks, so it is not safe to go explore the ecosystems around our school."

Four teachers used EcoMUVE in parallel to another ecology curriculum. These teachers usually encouraged students to compare different ecosystems in different curriculums. For instance, a grade 7-8 teacher from California, ID40, said that she used the EcoMUVE curriculum as support for a unit on ecosystems. This allowed her students to be able to compare and contrast the EcoMUVE pond with the San Francisco Bay wetlands ecosystem they studied.

Overall, teachers used the EcoMUVE curriculum as it best suited their own ecosystems science curriculum, and to facilitate implementation of their goals with that curriculum. In terms of modules, 33\% used the Pond module, 4\% used the Forest module, 36\% used both and 27\% used neither. So, the Forest module alone might be less suited in their curriculum than Pond module alone. Although respondents did 
not talk about meeting national standards, their different uses of the curriculum imply the fit with curricular objectives and standards.

RQ3 Perceptions of the impact on student engagement and learning: How do teachers perceive the impact of the EcoMUVE curriculum in terms of student engagement and learning?

23 of the 50 teachers who had used EcoMUVE specifically mentioned their students' engagement and enthusiasm. Teachers also mentioned that they found EcoMUVE promoted higher-level thinking, learning (e.g., ID52), recall (e.g., ID63), motivation (e.g., ID56), and found that it is self-differentiating (e.g., ID81). A few teachers specifically mentioned that the interaction with the virtual characters as part of problem-solving made the MUVE more engaging to students (e.g., ID59). One teacher with special needs students said that EcoMUVE was very effective to engage that group of students.

Some teachers reported that EcoMUVE helped students learn without feeling that what they do in EcoMUVE is schoolwork. Some students also downloaded the software on their personal computers and spent their free time further exploring the environment. Students' interest in interacting with the virtual world outside of their classroom is another indication of their engagement (Turkay, 2010).

Six teachers talked about how the authenticity of the environment helped student learning. Some reported that this authenticity facilitated students' ability to relate and apply what they learned in EcoMUVE to everyday life and to their fieldwork. ID19 from MA gave an example from one of her students' experiences:

I have a student who lives on Dudley Pond and her parents are very much involved in the care of the pond ecosystem. She went to a meeting, where they were discussion phosphates and nitrates and she came back the next day to say that for the first time she understood the science part of the meeting!

Teachers generally had very positive attitudes towards inquiry mechanics built in EcoMUVE. For instance, ID56 reported, "the data collection tools gave students opportunities to make and read graphs and practice interpreting them to solve the mystery." He added that the positive experience led him to seek out other science simulation games to use during for other units. Also, teachers liked the data collection mechanics and visual presentation. They described students' excitement about being able to see changes happening within the virtual ecosystem and the ability to graph data interactively (e.g., ID22).

Teachers reported that students used argumentation skills when interpreting data they collected in EcoMUVE to explain why fish died. In an example quote, ID94 said, "My favorite lesson was the students' final arguments. It was interesting to see the different arguments they came up with and how well they could use the data and other information to support their arguments."

Eight teachers reported that students had an understanding of pond and forest ecosystems and recalled the facts they learned in the curriculum. ID74 from VA said that she was initially worried that students would not recall what they learned with EcoMUVE because they responded as if it were a scavenger hunt. At the end, though, she found that students were able to make the necessary connections to show their understanding, and students used the data they had collected to defend their assumptions.

Several teachers said that students' interactions in the virtual world also made them realize the complexity of the process in understanding causality in ecosystems. As ID71 said, "... quite a few needed nudging to link all the weather factors, although most recognized eutrophication quite early in the process. They said, 'it's far more complex than we thought', which is exactly what I was hoping they'd conclude." Some 
teachers realized that EcoMUVE helped them learn about students' misconceptions so that they could modify lessons accordingly.

Teachers reported student learning with EcoMUVE that ranged from simply recalling names of items in the virtual ecosystem to explaining complex causal processes. The combination of learning mechanics built in the virtual world and lesson plans to encourage student inquiry and reasoning skills facilitated students' learning with the curriculum. These findings on teachers' perceptions on student engagement and learning mirror the results from the earlier study. This is encouraging since these teachers did not have any direct support from EcoMUVE team when implementing the curriculum into classroom teaching. Moreover, $92 \%$ of the participants said that they would use EcoMUVE during their next school year.

\section{CONCLUSIONS}

For the generalizability of the results, it was important to examine whether teachers who did not have any direct support from the EcoMUVE team had similar or different experiences from the teachers with whom we conducted our initial study. Our findings suggest that the independent, on-line teachers also largely found the EcoMUVE curriculum feasible and engaging and were able to modify it to achieve their classroom objectives.

These results are encouraging. Again we acknowledge that the on-line group is a self-selected population of willing adopters; educators who took the initiative to download the EcoMUVE software and curriculum, learn the materials for themselves, and then use them with their students. The survey results also include responses from teachers who choose not to use EcoMUVE, and a large percentage of our mailing list chose not to take the survey at all. However, it is an indicator of the growing interest in MUVE-based educational tools that we have an increasing number of teachers who are choosing to use a tool like EcoMUVE, even adopting it on their own, and we find through their self-reporting that these teachers perceive the MUVE-based curriculum to be effective and valuable in a variety of ways.

To promote wider adoption of multi-user virtual environments as an educational tool it is important to provide teachers clear language on the benefits of the technology for learning, and to support them in the process of technology adoption. We are in the beginning stages of developing a virtual world-based professional development curriculum for teachers who are interested in using EcoMUVE in their classroom, which we hope to pursue as the next step in promoting the feasibility and utility of 3D virtual environments in K-12 education.

Overall, we are heartened to see that instructional effectiveness and alignment to standards were not generally found to be concerns of the teachers who used EcoMUVE. As computer access improves across all schools, we can expect that technological barriers will fade. With increased accessibility, research on the effectiveness of immersive environments to support student learning is therefore becoming increasingly important.

\section{ACKNOWLEDGMENTS}

EcoMUVE research was supported by Institute of Education Sciences grant no. R305A080514. All opinions, findings, conclusions, or recommendations expressed here are those of the authors and do not necessarily reflect the views of the Institute for Education Sciences.

\section{REFERENCES}


Barab, S., Pettyjohn, P., Gresalfi, M., Volk, C., \& Solmou, M. (2012). Game-based curriculum and transformational play: Designing meaningfully positioning person, content, and context. Computers \& Education, 58(1), 518-533.

Barab, S., Thomas, M., Dodge, T., Carteaux, R., \& Tuzun, H. (2005). Making learning fun: Quest Atlantis, a game without guns. Educational Technology Research and Development, 53(1), 86-107.

Beals, K., and Willard, C. (2001). Environmental Detectives, Lawrence Hall of Science, University of California, Berkeley, CA

Clark, D., Nelson, B., Sengupta, P \& D’Angelo, C. (2009, October). Rethinking science learning through digital games and simulations: Genres, examples, and evidence, National Research Council, Committee for Learning Science: Computer Games, Simulations, and Education Workshop October 6-7, 2009

Dede, C. (2009). Immersive interfaces for engagement and learning. Science, 323(5910), 66-69.

Dickes, A., \& Sengupta, P. (2013). Learning Natural Selection in $4^{\text {th }}$ grade with Multi-Agent-Based Computational Models. Research in Science Education. 43(3), 921-953.

Ertmer, P.A. (2005). Teacher pedagogical beliefs: The final frontier in our quest for technology integration? Educational Technology Research and Development, 53(4), 25-39.

Grotzer, T.A., Kamarainen, A.M., Tutwiler, M.S., Metcalf, S.J., \& Dede, C.J. (2012, April) Learning to focus on processes and steady states in ecosystems dynamics using a virtual environment. Paper presented at the meeting of the American Educational Research Association (AERA) Conference, Vancouver, BC, Canada.

Ifenthaler, D., \& Schweinbenz, V. (2013). The acceptance of Tablet-PCs in classroom instruction: The teachers' perspectives. Computers in Human Behavior, 29(3), 525-534.

Jones, G., and Warren, S. (2011) Issues and Concerns of K-12 Educators on 3-D Multi-User Virtual Environments in Formal Classroom Settings, International Journal of Gaming and Computer-Mediated Simulations, 3(1), 1-12.

Kenny, R. F., \& McDaniel, R. (2011). The role teachers' expectations and value assessments of video games play in their adopting and integrating them into their classrooms. British Journal of Educational Technology, 42(2), 197-213.

Ketelhut, D. J., Nelson, B. C., Clarke, J. E., \& Dede, C. (2010). A multi-user virtual environment for building and assessing higher order inquiry skills in science. British Journal of Educational Technology 41(1), 56-68.

Klopfer, E., Osterweil, S., \& Salen, K. (2009). Moving Learning Games Forward: Obstacles, Opportunities and Openness (White Paper). Cambridge, MA: The Education Arcade, Massachusetts Institute of Technology.

Metcalf, S.J., Chen, J.A., Kamarainen, A.M., Frumin, K.M., Vickrey, T.L., Grotzer, T.A., Dede, C.J. (in press) Shifts in Student Motivation During Usage of a Multi-User Virtual Environment for Ecosystem Science, International Journal of Virtual and Personal Learning Environments.

Metcalf, S.J., Kamarainen, A., Tutwiler M.S., Grotzer, T.A. \& Dede, C. J. (2011). Ecosystem science learning via multi-user virtual environments. International Journal of Gaming and Computer-Mediated Simulations. 3(1)86-90. 
Metcalf, S.J., Tutwiler, M.S., Kamarainen, A.M., Grotzer, T.A., Dede, C.J. (2013, April) Multi-user virtual environments to promote middle school ecosystem science learning and attitudes about science, Paper presented at the meeting of the American Educational Research Association (AERA) Conference, San Francisco, CA.

Miranda, H., Russel, M. (2012). Understanding factors associated with teacher-directed student use of technology in elementary classrooms: A structural equation modeling approach. British Journal of Educational Technology, 43(4), 652-666.

Rice, J.W. (2007) New Media Resistance: Barriers to the Implementation of Computer Video Games in the Classroom. Journal of Educational Multimedia and Hypermedia, 16(3). 249-261

Schaller, D. T., Goldman, K. H., Spickelmier, G., Allison-Bunnell, S., \& Koepfler, J. (2009). Learning in the wild: What Wolfquest taught developers and game players. Museums and the web 2009: Proceedings. Toronto: Archives \& Museum Informatics.

Straub, Evan T. (2009). Understanding Technology Adoption: Theory and Future Directions for Informal Learning. Review of Educational Research, 79(2), 624-649.

Turkay, S. (2010). Student engagement and attitude change towards science when learning with a virtual world based curriculum: A case study. In Proceedings of World Conference on Educational Multimedia, Hypermedia and Telecommunications 2010 (pp. 248-257). Chesapeake, VA: AACE.

Venkatesh, V., Morris, M.G., Davis, G.B., \& Davis, F.D. (2003). User acceptance of information technology: Toward a unified view. MIS Quarterly, 27(3), 425-478. 